\title{
Análisis reproductivo de vacas Suizo Pardo x Cebú y Simmental x Cebú en condiciones tropicales
}

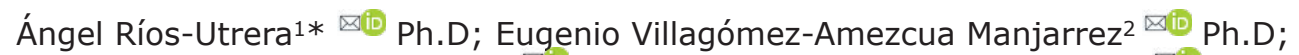 \\ Juan Prisciliano Zárate-Martínez ${ }^{凶 \mathbb{E}}$ Ph.D; René Carlos Calderón-Robles ${ }^{3} \bowtie \mathbb{B}$ M.Sc; \\ Vicente Eliezer Vega-Murillo ${ }^{1 凶}$ Ph.D.
}

\begin{abstract}
${ }^{1}$ Instituto Nacional de Investigaciones Forestales, Agrícolas y Pecuarias (INIFAP), Centro de Investigación Regional GolfoCentro, Campo Experimental La Posta. Km. 22.5 carretera federal Veracruz-Córdoba, Paso del Toro, Medellín, Veracruz, México. 2Instituto Nacional de Investigaciones Forestales, Agrícolas y Pecuarias (INIFAP), Centro Nacional de Investigación Disciplinaria en Microbiología Animal. Km. 15.5 carretera federal México-Toluca, Palo Alto, Ciudad de México, México.

${ }^{3}$ Instituto Nacional de Investigaciones Forestales, Agrícolas y Pecuarias (INIFAP), Centro de Investigación Regional GolfoCentro, Sitio Experimental Las Margaritas. Km. 18.5 carretera Hueytamalco-Tenampulco, Hueytamalco, Puebla, México.

*Correspondencia: rios.angel@inifap.gob.mx
\end{abstract}

Recibido: Abril 2019; Aceptado: Julio 2019; Publicado: Diciembre 2019.

\section{RESUMEN}

Objetivo. Comparar la fertilidad de vacas cruzadas Suizo Pardo x Cebú y Simmental x Cebú criadas en un ambiente tropical. Materiales y métodos. Se evaluaron características reproductivas de 185 vacas cruzadas Suizo Pardo x Cebú y Simmental x Cebú con diversos porcentajes de raza europea. El pastoreo de las vacas fue rotacional. El ordeño fue dos veces al día con la ayuda (amamantamiento) del becerro, el cual se mantuvo atado cerca de la vaca mientras ella se ordeñaba. Las características se evaluaron ajustando un modelo de mediciones repetidas (excepto para edad a primer parto). Periodo interparto, edad a primer parto, días abiertos, periodo parto-primer servicio y peso al parto fueron analizados con PROC MIXED de SAS. Tasa de gestación a primer servicio y servicios por concepción, se analizaron con PROC GENMOD del mismo programa. Resultados. Las vacas Simmental x Cebú se sirvieron después del parto 39 días antes $(p<0.05)$ y tuvieron 47 días abiertos menos $(p<0.05)$ que las Suizo Pardo x Cebú. El periodo interparto de las vacas Simmental x Cebú fue 45 días más corto $(p<0.05)$ que el de las Suizo Pardo x Cebú. Las vacas Simmental x Cebú pesaron 34 kg más al parto $(p<0.05)$ que las Suizo Pardo x Cebú. Conclusiones. Las vacas Simmental x Cebú tuvieron mejor fertilidad que las Suizo Pardo x Cebú.

Palabras clave: Análisis de mediciones repetidas, cruzamiento, edad a primer parto, periodo interparto, tasa de gestación, trópico (Fuente: $C A B$ ).

\section{ABSTRACT}

Objective. Compare the fertility of Brown Swiss $x$ Zebu and Simmental $x$ Zebu crossbred cows reared in a tropical environment. Materials and methods. Reproductive traits of 185 Brown Swiss $x$ Zebu and Simmental $x$ Zebu crossbred cows with diverse percentages of European breed were evaluated. Grazing of cows was rotational. The milking was twice daily with the help (suckling) of the calf, which was kept tied next to the dam while she was milked. Traits were evaluated fitting a repeated measures model (except for age at first calving). Calving interval, age at first calving, days open, interval from calving to first service, and weight at calving were analyzed with PROC MIXED of SAS. Pregnancy rate at first service and services per conception were analyzed with PROC GENMOD 
of the same software. Results. Simmental $\times$ Zebu cows started to re-bred 39 days earlier after calving $(p<0.05)$ and had 47 fewer days open $(p<0.05)$ than Brown Swiss $x$ Zebu cows. The calving interval of the Simmental $x$ Zebu cows was 45 days shorter $(p<0.05)$ than that of the Brown Swiss $x$ Zebu cows. Simmental $x$ Zebu cows were $34 \mathrm{~kg}$ heavier at calving $(p<0.05)$ than Brown Swiss $x$ Zebu cows. Conclusions. Simmental $x$ Zebu cows had better fertility than Brown Swiss $x$ Zebu cows.

Keywords: Age at first calving, calving interval, crossbreeding, pregnancy rate, repeated measures analysis, tropics (Source: $C A B$ ).

\section{INTRODUCCIÓN}

En numerosos países con clima tropical, el cruzamiento de Cebú con razas Bos taurus (Holstein, Jersey, Suizo Pardo) ha sido una práctica común en hatos de doble propósito, para mejorar rasgos de composición y producción de leche, salud, supervivencia y fertilidad. Entre estas características, se ha observado que la fertilidad tiene el mayor impacto en la eficiencia del hato.

El cruzamiento permite la introducción de genes favorables y obtiene ventaja de la complementariedad racial y la heterósis. La complementariedad racial permite a los criadores capitalizar las fortalezas de las diferentes razas, ya que ninguna raza es superior en todas las características que afectan la rentabilidad. En México, el sistema de producción de doble propósito está constituido principalmente por cruzas entre Cebú y Suizo Pardo, Holstein Friesian y Simmental $(1,2,3)$.

Varios estudios realizados en diferentes regiones del mundo han evaluado el desempeño reproductivo de vacas Holstein Friesian x Cebú $(4,5,6,7,8,9)$ o Jersey $x$ Cebú $(10,11)$, o han comparado el desempeño reproductivo de vacas puras indígenas y cruzadas Holstein Friesian x Cebú $(12,13)$, de vacas Holstein Friesian x Cebú y Jersey $x$ Cebú $(12,14,15)$, de vacas Cebú y 3/8 Simmental x 5/8 Cebú (16), de vacas Suizo Pardo $x$ Cebú y Holstein Friesian $x$ Cebú (17), y de vacas Holstein Friesian x Cebú y Simmental x Cebú $(18,19)$. Sin embargo, son muy escasos los artículos científicos relacionados con la evaluación reproductiva de vacas Suizo Pardo x Cebú y Simmental x Cebú bajo las mismas condiciones tropicales o subtropicales; aparentemente, solo se ha publicado un artículo relacionado con la comparación de estos dos últimos genotipos (1). Un estudio mexicano previo mostró que vacas Simmental x Cebú y Suizo Pardo x Cebú produjeron niveles similares de leche (3).
Con base en estos antecedentes, el objetivo del presente estudio fue comparar la fertilidad de vacas Suizo Pardo x Cebú y Simmental x Cebú criadas en un ambiente tropical.

\section{MATERIALES Y METÓDOS}

Sitio de estudio. El estudio se implementó en un hato bovino de doble propósito en la estación experimental Playa Vicente, que pertenece al Instituto Nacional de Investigaciones Forestales, Agrícolas y Pecuarias (INIFAP), y se localiza a $95 \mathrm{msnm}$, en los $17^{\circ} 19^{\prime}$ latitud norte y $95^{\circ} 41^{\prime}$ longitud oeste, en Veracruz, México. La región cuenta con clima tropical húmedo, temperatura media de $26.8^{\circ} \mathrm{C}$ y precipitación de $2200 \mathrm{~mm}$ al año (20).

Animales. En la tabla 1 se presenta el número de vacas evaluadas y de los padres y madres que se utilizaron para producirlas. Se evaluaron características reproductivas de 185 vacas cruzadas Suizo Pardo x Cebú y Simmental $x$ Cebú con diversos porcentajes de raza europea $(50.0,62.5$ o $75.0 \%)$.

Tabla 1. Número de vacas, padres y madres, por grupo genético.

\begin{tabular}{lccc}
\hline \multicolumn{1}{c}{ Grupo genético } & Vacas & Padres & Madres \\
\hline Cebú & - & - & 65 \\
Simmental & - & 21 & - \\
Suizo Pardo & - & 24 & - \\
1/2 Simmental x 1/2 Cebú & 36 & 2 & 21 \\
1/2 Suizo Pardo x 1/2 Cebú & 47 & 1 & 28 \\
3/4 Simmental x 1/4 Cebú & 35 & 2 & 4 \\
3/4 Suizo Pardo x 1/4 Cebú & 45 & 6 & 7 \\
$5 / 8$ Simmental x 3/8 Cebú & 7 & - & - \\
$5 / 8$ Suizo Pardo x 3/8 Cebú & 15 & 4 & 4 \\
Total & 185 & 60 & 129 \\
\hline
\end{tabular}

Las vacas evaluadas nacieron de 1981 a 2003 y se produjeron con 60 toros puros e híbridos con diversos porcentajes de raza Suizo Pardo o Simmental y 129 madres puras e híbridas con 
diversos porcentajes de raza Cebú. La raza Cebú de las madres puras fue Indubrasil. Las 129 madres se aparearon con los 60 toros mediante IA (en la gran mayoría de los casos) y monta natural. Las vacas de ambos grupos genéticos fueron manejadas juntas, de la misma manera, y pastorearon en los mismos potreros.

La tabla 2 presenta la forma en que se realizaron los cruzamientos para producir las 185 vacas evaluadas. Las vacas F1 se generaron con sementales Simmental o Suizo Pardo. Las vacas $75 \%$ europeo- $25 \%$ Cebú se generaron con sementales puros de raza europea y sementales $75 \%$ europeo- $25 \%$ Cebú; las vacas $62.5 \%$ europeo-37.5\% Cebú se produjeron con sementales $\mathrm{F} 1$ y $75 \%$ europeo-25\% Cebú. Además, las vacas $62.5 \%$ Suizo Pardo-37.5\% Bos indicus se generaron con sementales $62.5 \%$ europeo-37.5\% Cebú.

Alimentación. Las vacas se mantuvieron en pastoreo rotacional en praderas con Guinea (Panicum maximum) y Estrella Africana (Cynodon plectostachyus). Además, consumieron $2 \mathrm{~kg} /$ animal/d de un suplemento comercial con $70 \%$ de TND y $16 \%$ de PC, 30 días antes de parir y en cada ordeño hasta el secado. En el periodo de estiaje, las vacas se suplementaron con $15-20 \mathrm{~kg} /$ animal/d de caña japonesa picada (Saccharum sinense) o ensilaje de maíz (Zea mayz).

Inseminación artificial. Las vacas se inseminaron por primera vez cuando alcanzaron un peso corporal de $350 \mathrm{~kg}$. La observación de celos se efectuó durante $1 \mathrm{~h}$ en la mañana (de 06:00 a.m. a 07:00 a.m.) y $1 \mathrm{~h}$ en la tarde (de 05:00 p.m. a 06:00 p.m.), con la ayuda de un toro celador. La eficiencia de detección del celo fue $60 \%$. La inseminación de las vacas fue de la siguiente manera: aquellas que presentaron celo en la mañana se sirvieron en la tarde, y aquellas que lo presentaron en la tarde se inseminaron al siguiente día por la mañana, 12 h después de observado el celo, aproximadamente. La gestación se diagnosticó por palpación rectal $45 \mathrm{~d}$ después de la inseminación. Las vacas se desecharon principalmente por razones de pobre fertilidad.

Ordeño. El ordeño fue mecánico, dos veces al día, después de un amamantamiento ligero realizado por el becerro, para estimular la eyección de leche. Los becerros se mantuvieron atados, a un costado de las vacas, mientras ellas fueron ordeñadas. La producción de leche de cada vaca se registró en cada ordeño. Durante los tres primeros meses de lactancia, se ordeñaron tres cuartos, dejando uno para consumo de leche del becerro, más la leche residual de los tres cuartos ordeñados.

A partir de los 91 días de lactancia hasta que el becerro se destetó, se ordeñaron los cuatro pezones, dejando para la alimentación del becerro solamente la leche residual. Después del ordeño, se permitió a los becerros mamar $1 \mathrm{~h}$, aproximadamente. Después de ello, los becerros se separaron de las vacas. Posterior al destete, los becerros solo se usaron para estimular la salida de leche hasta el secado de las vacas, que se realizó a los 7 meses de gestación o cuando produjeron menos de $3 \mathrm{~kg}$ de leche por día.

Variables de respuesta. Se analizaron registros de edad a primer parto, periodo partoprimer servicio, días abiertos, periodo interparto, servicios por concepción, tasa de gestación y peso al parto. Días abiertos se definió como el intervalo (días) del parto a la concepción; esta característica refleja la tasa de parto y la capacidad de la hembra para ciclar y manifestar estro. Tasa de gestación a primer servicio se definió como una variable binaria; por lo tanto, si una hembra quedó gestante después del servicio, se asignó un valor de 1 ; de lo contrario, se asignó un valor de 0 .

Tabla 2. Apareamientos realizados para producir las vacas Bos taurus x Bos indicus ${ }^{a}$

\begin{tabular}{cccccc}
\hline \multirow{2}{*}{ Padre } & \multicolumn{5}{c}{ Madre } \\
\cline { 2 - 6 } & C & 1S1C & 1P1C & 3S1C & 3P1C \\
\hline $\mathrm{S}$ & $50 \% \mathrm{~S}-50 \% \mathrm{C}$ & $75 \% \mathrm{~S}-25 \% \mathrm{C}$ & & & \\
$\mathrm{P}$ & $50 \% \mathrm{P}-50 \% \mathrm{C}$ & & $75 \% \mathrm{P}-25 \% \mathrm{C}$ & & \\
$1 \mathrm{~S} 1 \mathrm{C}$ & & & $62.5 \% \mathrm{~S}-37.5 \% \mathrm{C}$ & \\
$1 \mathrm{P} 1 \mathrm{C}$ & & & & $75 \% \mathrm{~S}-25 \% \mathrm{C}$ & \\
$3 \mathrm{~S} 1 \mathrm{C}$ & & $62.5 \% \mathrm{~S}-37.5 \% \mathrm{C}$ & & $75 \% \mathrm{P}-25 \% \mathrm{C}-37.5 \% \mathrm{C}$ \\
$3 \mathrm{P} 1 \mathrm{C}$ & & & $62.5 \% \mathrm{P}-37.5 \% \mathrm{C}$ & & $62.5 \% \mathrm{P}-37.5 \% \mathrm{C}$ \\
$5 \mathrm{P} 3 \mathrm{C}$ & & & & & \\
\hline
\end{tabular}

${ }^{a} \mathrm{C}=$ Cebú, $\mathrm{S}=$ Simmental, $\mathrm{P}=$ Suizo Pardo, $1 \mathrm{~S} 1 \mathrm{C}=1 / 2$ Simmental $\times 1 / 2$ Cebú, $1 \mathrm{P} 1 \mathrm{C}=1 / 2$ Suizo Pardo $\times 1 / 2$ Cebú, $3 \mathrm{~S} 1 \mathrm{C}=3 / 4$ Simmental $\times 1 / 4$ Cebú, $3 \mathrm{P} 1 \mathrm{C}=3 / 4$ Suizo Pardo $\times 1 / 4$ Cebú, 5P3C= 5/8 Suizo Pardo $\times 3 / 8$ Cebú 
Análisis estadísticos. Edad a primer parto se analizó con el procedimiento MIXED de SAS (21) con un modelo simple que incluyó vaca anidada en grupo genético de la vaca, y padre de la vaca anidado en grupo genético del padre como efectos aleatorios, y época de parto, grupo genético, y año de parto como efectos fijos.

Las características restantes se analizaron con un modelo de mediciones repetidas que incluyó vaca anidada en grupo genético de la vaca, y padre de la vaca anidado en grupo genético del padre como efectos aleatorios (excepto para tasa de gestación y servicios por concepción), y año de parto, número de lactancia, grupo genético de la vaca y época de parto como efectos fijos. Además, para tasa de gestación a primer servicio, el modelo incluyó fase de lactancia (Fase 1: de 1 a 50 d; Fase 2: de 51 a 100 d; Fase 3: de 101 a 150 d; y Fase 4: $\geq 151$ d postparto).

Días abiertos, peso al parto, periodo parto-primer servicio y periodo interparto se analizaron con PROC MIXED de SAS (21); tasa de gestación y servicios por concepción se analizaron con PROC GENMOD del mismo programa. Para servicios por concepción, se especificó una distribución Poisson en la declaración del modelo; en el análisis estadístico de la tasa de gestación se especificó una distribución binomial y se usó una función liga logit.

El modelo estadístico para analizar peso al parto, días abiertos, periodo parto-primer servicio y periodo interparto se ajustó preliminarmente probando diferentes estructuras de covarianzas orden, auto-regresiva heterogénea, simetría compuesta, simetría compuesta heterogénea, simple, Toeplitz, Toeplitz heterogénea y sin estructura) para proporcionar el mejor ajuste a los datos.

Las estructuras de covarianzas que se probaron para analizar tasa de gestación y servicios por concepción fueron auto-regresiva de primer orden, simetría compuesta, independiente, Toeplitz y sin estructura. La selección de la estructura de covarianzas apropiada para días abiertos, periodo parto-primer servicio, peso al parto y periodo interparto se basó en los criterios de información de ajuste de Akaike, de segundo orden y Bayesiano de Schwarz. Para tasa de gestación y servicios por concepción, la estructura de covarianzas apropiada se seleccionó con base en el criterio de información de ajuste de cuasi-verosimilitud. (ante-dependencia, auto-regresiva de primer

\section{RESULTADOS}

La tabla 3 resume las características de los datos para todas las variables de respuesta. Las medias no ajustadas de periodo interparto, servicios por concepción, edad a primer parto, periodo partoprimer servicio, días abiertos, tasa de gestación a primer servicio y peso al parto fueron: 447.5 d, 2.1 servicios, 36.1 meses, $119.5 \mathrm{~d}, 162.1 \mathrm{~d}$, $43.9 \%$, y $482.4 \mathrm{~kg}$, respectivamente.

Tabla 3. Estadísticas descriptivas.

\begin{tabular}{lcccccc}
\hline Variable $^{a}$ & n & Media & Dev Est & CV (\%) & Mínimo & Máximo \\
\hline EPP (meses) & 176 & 36.1 & 7.2 & 19.9 & 23.4 & 56.0 \\
PPS (días) & 641 & 119.5 & 78.7 & 65.9 & 7 & 906 \\
SXC & 595 & 2.1 & 1.3 & 61.9 & 1 & 8 \\
DA (días) & 596 & 162.1 & 104.9 & 64.7 & 7 & 926 \\
TG (\%) & 595 & 43.9 & 49.7 & 113.2 & 0 & 100 \\
PIP (días) & 596 & 447.5 & 100.1 & 22.4 & 298 & 975 \\
PP (kg) & 655 & 482.4 & 74.0 & 15.3 & 285 & 770 \\
\hline
\end{tabular}

aEPP = edad a primer parto; $\mathrm{PPS}=$ periodo parto-primer servicio; $\mathrm{SXC}=$ servicios por concepción; $\mathrm{DA}=$ días abiertos; $\mathrm{TG}=$ tasa de gestación a primer servicio; $\mathrm{PIP}=$ periodo interparto; $\mathrm{PP}=$ peso al parto.

Los criterios de información de ajuste de Akaike, de segundo orden, Bayesiano de Schwarz y de cuasi-verosimilitud se presentan en la tabla 4.

Table 4. Criterios de información de ajuste de Akaike (AIC), segundo orden (AICC), Bayesiano de Schwarz (BIC) y cuasi-verosimilitud (QIC).

\begin{tabular}{|c|c|c|c|c|}
\hline \multirow{2}{*}{$\begin{array}{c}\text { Variable/Estructura de } \\
\text { covarianzas }\end{array}$} & \multicolumn{4}{|c|}{ Criterio de informacióna } \\
\hline & AIC & AICC & BIC & QIC \\
\hline \multicolumn{5}{|l|}{ Servicios por concepciónb } \\
\hline Auto-regresiva de primer orden & - & - & - & 879.33 \\
\hline Simetría compuesta & - & - & - & 881.01 \\
\hline Independiente & - & - & - & 880.28 \\
\hline Toeplitz & - & - & - & 881.54 \\
\hline \multicolumn{5}{|l|}{ Tasa de gestación a primer serviciob } \\
\hline Auto-regresiva de primer orden & - & - & - & 825.51 \\
\hline Simetría compuesta & - & - & - & 825.37 \\
\hline Independiente & - & - & - & 825.46 \\
\hline Toeplitz & - & - & - & 825.52 \\
\hline \multicolumn{5}{|l|}{ Periodo parto-primer servicioc } \\
\hline Simple & \multicolumn{3}{|c|}{6584.26584 .26593 .9} & - \\
\hline Auto-regresiva de primer orden & \multicolumn{3}{|c|}{6585.56585 .66598 .6} & - \\
\hline \multicolumn{5}{|l|}{ Días abiertos ${ }^{c}$} \\
\hline Simple & \multicolumn{3}{|c|}{6375.66375 .76385 .4} & - \\
\hline Auto-regresiva de primer orden & \multicolumn{3}{|c|}{6377.66377 .76390 .6} & - \\
\hline \multicolumn{5}{|l|}{ Periodo interpartoc } \\
\hline Simple & \multicolumn{3}{|c|}{6305.46305 .56315 .2} & - \\
\hline Auto-regresiva de primer orden & 6304.0 & 6304.1 & 6317.0 & - \\
\hline Simetría compuesta & 6317.4 & 6317.5 & 6327.2 & - \\
\hline \multicolumn{5}{|l|}{ Peso al partoc } \\
\hline Simple & \multicolumn{2}{|c|}{6288.26288 .3} & 6298.0 & - \\
\hline \multicolumn{4}{|c|}{ Auto-regresiva de primer orden 6284.16284 .16297 .1} & - \\
\hline
\end{tabular}


Las estructuras de covarianzas apropiadas usadas en los modelos definitivos fueron: auto-regresiva de primer orden para peso al parto y servicios por concepción; simetría compuesta para tasa de gestación; y simple para periodo interparto, periodo parto-primer servicio y días abiertos.

La significación estadística de los efectos genéticos y ambientales se muestra en la tabla 5. La vaca anidada en grupo genético de la vaca fue una fuente de variación significativa para peso al parto $(p<0.0001)$, días abiertos $(p<0.0075)$, edad a primer parto $(p<0.0001)$, periodo partoprimer servicio $(p<0.0244)$ y periodo interparto $(p<0.0072)$. Padre de la vaca anidado en grupo genético del padre fue significativo para peso al parto $(p<0.0206)$, días abiertos $(p<0.0107)$, periodo parto-primer servicio $(p<0.0278)$ y periodo interparto $(p<0.0125)$. El grupo genético explicó la variación en días abiertos $(p<0.0023)$, periodo interparto $(p<0.0018)$, periodo parto-primer servicio $(p<0.0002)$ y peso al parto $(p<0.0008)$. Número de lactancia fue una fuente de variación significativa para días abiertos $(p<0.0001)$, peso al parto $(p<0.0001)$, periodo interparto $(p<0.0001)$, periodo parto-primer servicio $(p<0.0001)$ y tasa de gestación $(p<0.0130)$.

Las medias ajustadas para las variables de respuesta analizadas se muestran en la taba 6 . Las vacas Simmental $x$ Cebú se sirvieron después del parto 39 días antes $(p<0.05)$, tuvieron 47 días abiertos menos $(p<0.05)$ y periodo interparto 45 días más corto $(p<0.05)$ y fueron $34 \mathrm{~kg}$ más pesadas $(\mathrm{p}<0.05)$ al parto que las vacas Suizo Pardo x Cebú.

Tabla 5. Niveles de significancia estadística de los efectos fijos y aleatorios para las variables de respuesta.

\begin{tabular}{|c|c|c|c|c|c|c|c|}
\hline \multirow{2}{*}{ Efecto } & \multicolumn{7}{|c|}{ Variable de respuesta $^{a}$} \\
\hline & EPP & PPS & sxc & DA & TG & PIP & PP \\
\hline$V a c a^{b}$ & $<0.0001$ & 0.0244 & --- & 0.0075 & --- & 0.0072 & $<0.0001$ \\
\hline Padre $^{c}$ & 0.0623 & 0.0278 & --- & 0.0107 & --- & 0.0125 & 0.0206 \\
\hline Grupo genético & 0.1315 & 0.0002 & 0.8939 & 0.0023 & 0.3617 & 0.0018 & 0.0008 \\
\hline Año (A) & $<0.0001$ & $<.0001$ & 0.0042 & $<0.0001$ & 0.0358 & $<0.0001$ & $<0.0001$ \\
\hline Época (E) & 0.1155 & 0.6925 & 0.3036 & 0.7028 & 0.8084 & 0.9605 & 0.2618 \\
\hline Lactanciad $^{d}$ & --- & $<.0001$ & 0.5058 & $<0.0001$ & 0.0130 & $<0.0001$ & $<0.0001$ \\
\hline$A \times E$ & --- & 0.0392 & --- & 0.0002 & --- & 0.0001 & 0.0010 \\
\hline Fase & --- & --- & --- & --- & 0.4262 & --- & --- \\
\hline
\end{tabular}

aEPP = edad a primer parto; PPS= periodo parto-primer servicio; $\mathrm{SXC}=$ servicios por concepción; $\mathrm{DA}=$ días abiertos; $\mathrm{TG}=$ tasa de gestación a primer servicio; $\mathrm{PIP}=$ periodo interparto; $\mathrm{PP}=$ peso al parto; bVaca anidada en grupo genético de la vaca; cPadre de la vaca anidado en grupo genético del padre; dLactancia= número de lactancia; ${ }^{\mathrm{F} F a s e=}$ Fase de la lactancia.

Tabla 6. Medias de cuadrados mínimos y errores estándar para edad a primer parto (EPP), periodo parto-primer servicio (PPS), servicios por concepción (SXC), días abiertos (DA), tasa de gestación a primer servicio (TG), periodo interparto (PIP) y peso al parto (PP), por grupo genético, época de parto, número de lactancia y fase de la lactancia.

\begin{tabular}{|c|c|c|c|c|c|c|c|}
\hline & \multicolumn{7}{|c|}{ Variable de respuesta } \\
\hline & EPP & PPS & SXC & DA & TG & PIP & PP \\
\hline \multicolumn{8}{|c|}{$\overline{\text { Grupo genéticod }^{d}}$} \\
\hline $\mathrm{P} \times \mathrm{C}$ & $36.5 \pm .62^{\mathrm{a}}$ & $143 \pm 6.2^{\mathrm{a}}$ & $2.1 \pm .08^{a}$ & $192 \pm 9.6^{a}$ & $41 \pm 3^{a}$ & $476 \pm 9.1^{a}$ & $451 \pm 6.3^{a}$ \\
\hline $\mathrm{S} \times \mathrm{C}$ & $38.0 \pm .82^{\mathrm{a}}$ & $104 \pm 7.0^{b}$ & $2.1 \pm .09^{a}$ & $145 \pm 10.8^{b}$ & $45 \pm 4^{a}$ & $431 \pm 10.3^{b}$ & $485 \pm 7.2^{b}$ \\
\hline \multicolumn{8}{|c|}{ Época de parto } \\
\hline Fría & $38.1 \pm .79^{a}$ & $120 \pm 6.3^{a}$ & $2.1 \pm .10^{a}$ & $167 \pm 9.5^{\mathrm{a}}$ & $43 \pm 5^{\mathrm{a}}$ & $453 \pm 8.9^{a}$ & $470 \pm 5.5^{\circ}$ \\
\hline Seca & $37.5 \pm .75^{\mathrm{a}}$ & $126 \pm 6.7^{a}$ & $2.1 \pm .12^{\mathrm{a}}$ & $173 \pm 9.8^{a}$ & $41 \pm 4^{a}$ & $455 \pm 9.3^{a}$ & $464 \pm 5.6^{\circ}$ \\
\hline Lluviosa & $36.3 \pm .72^{\mathrm{a}}$ & $124 \pm 5.7^{a}$ & $2.0 \pm .09^{a}$ & $165 \pm 8.4^{a}$ & $45 \pm 4^{a}$ & $452 \pm 7.9^{a}$ & $470 \pm 5.2^{\circ}$ \\
\hline \multicolumn{8}{|c|}{ Número lactancia } \\
\hline 1 & & $144 \pm 6.3^{a}$ & $2.2 \pm .10^{\mathrm{a}}$ & $200 \pm 9.2^{\mathrm{a}}$ & $34 \pm 4^{a}$ & $487 \pm 8.7^{\mathrm{a}}$ & $428 \pm 5.3^{\circ}$ \\
\hline 2 & & $125 \pm 6.9^{b}$ & $2.0 \pm .12^{\mathrm{a}}$ & $161 \pm 9.9^{b}$ & $52 \pm 5^{b}$ & $445 \pm 9.4^{b}$ & $469 \pm 5.5^{b}$ \\
\hline$\geq 3$ & & $102 \pm 5.8^{c}$ & $2.0 \pm .08^{a}$ & $144 \pm 8.7^{b}$ & $44 \pm 4^{\mathrm{ab}}$ & $428 \pm 8.3^{b}$ & $506 \pm 5.5$ \\
\hline \multicolumn{8}{|c|}{ Fase de lactanciae } \\
\hline 1 & & & & & $37 \pm 6^{a}$ & & \\
\hline 2 & & & & & $45 \pm 4^{a}$ & & \\
\hline 3 & & & & & $43 \pm 4^{a}$ & & \\
\hline 4 & & & & & $48 \pm 5^{\mathrm{a}}$ & & \\
\hline
\end{tabular}

$a, b, c$ Medias con diferente superíndice dentro de la misma columna en cada factor son diferentes $(P<0.05)$.

dP $\times$ C = Suizo Pardo $\times$ Cebú; $S \times C=$ Simmental $\times$ Cebú.

e $1=$ de 1 a $50 \mathrm{~d} ; 2=$ de 51 a $100 \mathrm{~d} ; 3=$ de 101 a $150 \mathrm{~d} ; 4=\geq 151$ d postparto. 
Las vacas con tres lactancias tuvieron menos $(p<0.05)$ días a primer servicio después del parto que las de una o dos lactancias. Las vacas con dos lactancias tuvieron menos $(p<0.05)$ días a primer servicio después del parto que las de una lactancia. Las vacas con dos o tres lactancias tuvieron menos días abiertos $(p<0.05)$ e intervalos entre partos más cortos $(p<0.05)$ que las de una lactancia. Las vacas con dos lactancias tuvieron mayor $(\mathrm{p}<0.05)$ tasa de gestación a primer servicio que las de una lactancia; la tasa de gestación de las vacas con tres lactancias fue intermedia. Las vacas con tres lactancias fueron más pesadas al parto $(p<0.05)$ que las de una o dos lactancias. Las vacas con dos lactancias fueron más pesadas al parto $(p<0.05)$ que las de una lactancia.

\section{DISCUSIÓN}

Artículos científicos que comparan la capacidad reproductiva de vacas Simmental x Cebú y Suizo Pardo x Cebú son muy escasos en la literatura, por lo tanto, en la mayoría de los casos, vacas Simmental $x$ Cebú fueron comparadas con vacas Holstein Friesian x Cebú; sin embargo, artículos científicos que comparan el desempeño reproductivo de estos dos últimos genotipos son también limitados.

Las medias de cuadrados mínimos para edad a primer parto y periodo interparto reportadas para los grupos genéticos Simmental x Cebú y Suizo Pardo x Cebú del presente estudio son similares a las reportadas para el grupo genético Suizo Pardo x Cebú en condiciones tropicales de Yucatán, México (22), y para el grupo genético Holstein Friesian x Cebú en granjas lecheras de pequeños agricultores de Etiopía (5).

En un estudio realizado en el trópico húmedo de México, los genotipos Suizo Pardo x Cebú y Simmental x Cebú tuvieron similares edades a primer parto y periodos interparto (1). Estos resultados concuerdan parcialmente con los del presente estudio, en el cual los genotipos Simmental x Cebú y Suizo Pardo x Cebú tuvieron similar edad a primer parto $(p>0.05)$, pero el genotipo Simmental $x$ Cebú tuvo periodos interparto más cortos $(p<0.05)$ que el genotipo Suizo Pardo x Cebú.

Investigadores colombianos (19) observaron que el intervalo del parto al primer calor de vacas Simmental x Cebú fue 48.8 días más corto que el de vacas Holstein x Cebú; sin embargo, estos investigadores también encontraron que estos grupos genéticos no difirieron significativamente en la edad a primer calor. En un estudio realizado en Etiopía (18) se encontró que el intervalo entre partos de vacas $3 / 4$ Simmental x 1/4 Horro (Cebú) fue 178 días más corto que el de vacas $3 / 4$ Friesian $x$ 1/4 Horro (Cebú). En contraste, en un estudio realizado en Brasil (23) vacas Simmental x Cebú y Holstein Friesian x Cebú tuvieron similares intervalos entre partos.

La menor fertilidad de las vacas Suizo Pardo $\mathrm{x}$ Cebú encontrada en el presente estudio se puede deber a una mayor intensidad de selección para producción de leche en la raza Suizo Pardo que en la raza Simmental. Se ha demostrado que la producción de leche tiene una correlación genética desfavorable con la fertilidad, lo que indica que la selección para mayor producción de leche disminuye la fertilidad (24).

En varios estudios, la evaluación reproductiva de vacas cruzadas Bos taurus x Bos indicus ha revelado que vacas con dos o tres lactancias tienen intervalos entre partos más cortos que vacas con una lactancia $(1,13,15,22)$, lo cual concuerda con los presentes hallazgos. Esto se explica, en parte, por el hecho de que las vacas primerizas no han completado su desarrollo corporal, por lo que parte del alimento que consumen lo destinan a este fin, sacrificando su producción de leche y fertilidad (22). En contraste, en un estudio realizado en Tabasco, México (9), con vacas Holstein Friesian x Cebú, vacas con tres lactancias tuvieron intervalos entre partos más largos que vacas con una lactancia (440 vs 414 días), hallazgo que no concuerda con el presente resultado; también en discordancia están los resultados obtenidos con vacas Jersey $x$ Red Sindhi en la India, donde vacas con una, dos o tres lactancias tuvieron similares intervalos entre partos (11). La discrepancia con este último estudio puede deberse a que las hembras de reemplazo tuvieron una excelente alimentación, lo cual resultó en un buen desarrollo corporal antes de iniciar su vida reproductiva.

En la presente investigación, la tasa de gestación a primer servicio no fue afectada por la fase de lactancia. Por el contrario, en un cruce dialélico con Holstein Friesian y Suizo Pardo (25), vacas en Fase 4 de la lactancia ( $\geq 151 \mathrm{~d}$ postparto) tuvieron mayor tasa de gestación a primer servicio que vacas en Fase 1 (de 1 a 50 d postparto) y 2 (de 51 a 100 d postparto) de la lactancia (63\% vs 44 y $50 \%$, respectivamente), y vacas en Fase 3 (de 101 a 150 d postparto) fueron 
superiores a vacas en Fase 1 ( $56 \%$ vs $44 \%$ ); sin embargo, la discrepancia entre estudios pudo deberse a diferencias en los genotipos evaluados y prácticas de manejo del hato. En hatos lecheros, los becerros son separados de sus madres 4-5 d después del parto, pero en hatos de doble propósito los becerros se mantienen atados, a un costado de sus madres, mientras ellas son ordeñadas. Además, durante los primeros meses de lactancia, solo se ordeñan tres pezones, dejando un pezón para consumo de leche del becerro, más la leche residual de los tres pezones ordeñados. La presencia del becerro y el amamantamiento alteran la interacción entre hipotálamo, hipófisis y ovarios, disminuyendo la liberación de $\mathrm{GnRH}$, lo cual conduce a insuficientes pulsos de $\mathrm{LH}$, evitando que se presente la ovulación (26).
En conclusión, las vacas Simmental x Cebú fueron más pesadas al parto y tuvieron intervalos del parto al primer servicio, del parto a la gestación, y del parto al próximo parto más cortos que las Suizo Pardo x Cebú. Esto sugiere que vacas Simmental $x$ Cebú son una mejor alternativa para la producción pecuaria en las regiones tropicales que vacas Suizo Pardo x Cebú.

\section{Conflicto de interés}

Los autores no tienen ningún conflicto de intereses.

\section{REFERENCIAS}

1. Osorio-Arce MM, Segura-Correa JC. Efectos raciales y ambientales sobre edad al primer parto e intervalo entre partos de vacas Brahman y sus cruces en el trópico-húmedo de México. Livest Res Rural Develop. 2010; 22(8):1-10. http://www.Irrd.org/Irrd22/8/ osor22148.htm

2. Orantes-Zebadúa MA, Platas-Rosado D, Córdoba-Ávalos V, Santos-Lara MC, Córdoba-Ávalos A. Caracterización de la ganadería de doble propósito en una región de Chiapas, México. Ecosist Rec Agropec. 2014; 1(1):49-58. http://era.ujat. $\mathrm{mx/}$ index.php/rera/article/view/6/578

3. Ríos-Utrera A, Hernández-Hernández VD, Villagómez-Amezcua Manjarréz E, ZárateMartínez JP. Producción láctea de vacas Simmental x Cebú y Suizo Pardo x Cebú en clima tropical. Agron. Mesoam. 2015; 26(1):17-25. https://doi.org/10.15517/ am.v26i1.16891

4. Nuraddis I, Ashebr A, Shiferaw M. Assessment of reproductive performance of cross breed dairy cows (Holstein Friesian x Zebu) in Gondar Town. Global Vet. 2011; 6(6):561-566. https://www.idosi.org/gv/ GV6(6)11/12.pdf

5. Moges N. Study on reproductive performance of crossbred dairy cows under small holder conditions in and around Gondar, North Western Ethiopia. J Reprod Inf. 2012; 3(3):38-41. https://doi.org/10.5897/ IJLP11.055
6. Duguma B, Kechero $Y$, Janssens GPJ. Productive and reproductive performance of Zebu x Holstein-Friesian crossbred dairy cows in Jimma Town, Oromia, Ethiopia. Global Vet. 2012; 8(1):67-72. https://www. idosi.org/gv/GV8(1)12/12.pdf

7. Obese FY, Acheampong DA, Darfour-Oduro KA. Growth and reproductive traits of Friesian $x$ Sanga crossbred cattle in the Accra plains of Ghana. Afr J F Agric Nut Develop. 2013; 13(2):7357-7371. https:// www.ajol.info/index.php/ajfand/article/ view/87460

8. Kumar J, Singh YP, Kumar S, Singh R, Kumar R, Kumar P. Genetic analysis of reproductive performance of Frieswal cattle at Military Farm, Ambala. Vet World. 2015; 8(9):1032-1037. https://doi.org/10.14202/ vetworld.2015.1032-1037

9. Arce RC, Aranda IEM, Osorio AMM, González GR, Díaz RP, Hinojosa CJA. Evaluación de parámetros productivos y reproductivos en un hato de doble propósito en Tabasco, México. Rev Mex Cienc Pecu. 2017; 8(1):8391. https://doi.org/10.22319/rmcp. v8i1.4347

10. Varaprasad AR, Raghunandan T, Kumar MK, Prakash, MG. Studies on the reproductive performance of Jersey $x$ Sahiwal cows in Chittoor district of Andhra Pradesh. Int J Agric Sci Vet Med. 2013; 8(14):52-57. https://doi.org/10.5897/AJAR2013.6999 
11. Vinothraj S, Subramaniyan A, Venkataramanan R, Joseph C, Sivaselvam SN. Genetic evaluation of reproduction performance of Jersey $\times$ Red Sindhi crossbred cows. Vet World. 2016; 9(9):1012-1017. https://doi.org/10.14202/ vetworld.2016.1012-1017

12. Kebede G, Kebede M, Midexa T, Eshetu S. Comparative reproductive performance of Horro (Zebu) with Horro x Friesian and Horro $x$ Jersey females in sub humid environments of Bako. Livest Res Rural Develop. 2011; 23(8):1-6. http://www.Irrd.org/Irrd23/8/ Kebe23171.htm

13. Kumar N, Eshetie A, Gebrekidan B, Gurmu EB. Reproductive performance of indigenous and HF crossbred dairy cows in Gondar, Ethiopia. IOSR-JAVS. 2014; 7(1):56-61. https://doi.org/10.9790/2380-07155661

14. Yifat D, Kelay B, Bekana M, Lobago F, Gustafsson H, Kindahl H. Study on reproductive performance of crossbred dairy cattle under smallholder conditions in and around Zeway, Ethiopia. Livest Res Rural Develop. 2009; 21(6):1-6. http://www.Irrd. org/Irrd21/6/yifa21088.htm

15. Hussain J, Roychoudhury R, Das GC, Mili DC, Goswami RN. Reproductive performance of dairy cows under field condition of Assam State. Indian J Anim Res. 2012; 46(2): 180183. https://arccjournals.com/journal/ indian-journal-of-animal-research/ARCC441

16. García-Díaz JR, Scull SJ, Sarria SY, Pérez-Bello A, Hernández-Barreto M. Comportamiento reproductivo de los genotipos Cebú y $5 / 8$ Cebú x 3/8 Simmental en la región central de Cuba. Rev Prod Anim. 2018; 30(2):4451. https://revistas. reduc.edu.cu/index. $\mathrm{php/rpa/article/view/2369/2134}$

17. Zárate-Martínez JP, Esqueda-Esquivel VA, Vinay-Vadillo JC, Jácome-Maldonado SM. Evaluación económico-productiva de un sistema de producción de leche en el trópico. Agron Mesoam. 2010; 21(2):255-265. https://doi.org/10.15517/am.v21i2.4887

18. Kebede B. Estimation of additive and nonadditive genetic effects for growth, milk yield and reproduction traits of crossbred (Bos taurus $x$ Bos indicus) cattle in the wet and dry environments in Ethiopia. [Dissertation]. Cornell University; 1992. https://doi.org/10.1046/j.1439$\underline{0388.2003 .00374 . x}$
19. Grajales LH, Hernández VA Prieto E. Caracterización fisiológica del periodo posparto en cuatro grupos raciales bovinos en el trópico colombiano. Rev MVZ Córdoba. 2010; 15(1):1916-1924. https://doi. org/10.21897/rmvz.329

20. García E. Modificaciones al sistema de clasificación climática de Köppen. Universidad Nacional Autónoma de México. 1988. Pp. 109-110. http://www.igeograf.unam.mx/ sigg/utilidades/docs/pdfs/publicaciones/ geo siglo21/serie lib/modific al sis.pdf

21. SAS. SAS/STAT. Version 9.3. 4th ed. SAS Institute: Cary, USA; 2011. https://support. sas.com/en/software/sas-stat-support.html

22. Mejía-Baustista GT, Magaña JG, SeguraCorrea JC, Delgado R, Estrada-León RJ. Comportamiento reproductivo y productivo de vacas Bos indicus, Bos taurus y sus cruces en un sistema de producción vaca:cría en Yucatán, México. Trop Subtrop Agroecosys. 2010；12:289-301. http://www. revista. ccba.uady.mx/ojs/index.php/TSA/article/ view/403/375

23. McManus $C$, Saueressig $M G$, Falcão RA, Serrano G, Marcelino KRA, Paludo GR. Componentes reprodutivos e produtivos no rebanho de corte da Embrapa Cerrados. R Bras Zootec. 2002; 31(2):648-657. https://doi. org/10.1590/S1516-35982002000300015

24. Ríos-Utrera A, Calderón-Robles RC, GalavízRodríguez JR, Vega-Murillo VE, LagunesLagunes J. Genetic correlations of days open with milk yield and metabolic weight in Holstein and Brown Swiss cows. Rev Científ, FCV-LUZ. 2015; 25(1):51-56. http://www. saber.ula.ve/handle/123456789/40015

25. Calderón-Robles RC; Ríos-Utrera A, VegaMurillo VE, Montaño-Bermúdez M, MartínezVelázquez G, Román-Ponce SI, et al. Reproduction of Holstein and Brown Swiss cows and of their $\mathrm{F} 1$ reciprocal crosses raised in a Mexican subtropical environment. J Anim Plant Sci. 2017; 27(6):1816-1821. http:// www.thejaps.org.pk/docs/v-27-06/09.pdf

26. Williams GL, Gazal OS, Guzman Vega GA, Stanko RL. Mechanisms regulating sucklingmediated anovulation in the cow. Anim Reprod Sci. 1996; 42(1-4):289-297. https:// doi.org/10.1016/0378-4320(96)01531-X 